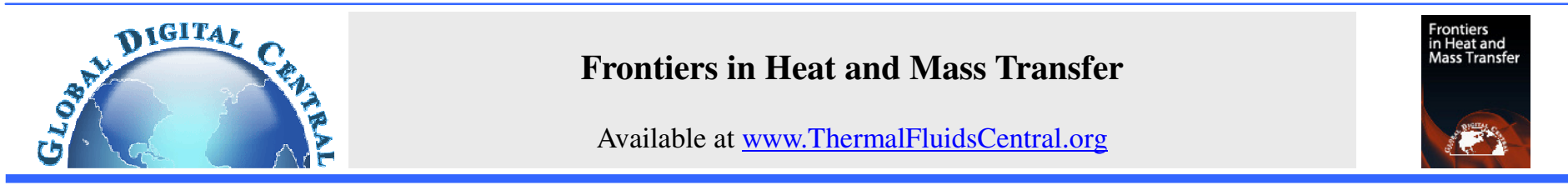

\title{
HEAT TRANSFER IN A MICROTUBE OR MICROCHANNEL WITH PROTRUSIONS
}

\author{
Muhammad M. Rahman*, Phaninder Injeti \\ Department of Mechanical Engineering, University of South Florida, Tampa, Florida 33620, USA
}

\begin{abstract}
This paper presents the effects of protrusions on heat transfer in a microtube and in a two-dimensional microchannel of finite wall thickness. The effects of protrusion shape, size, and number were investigated. Calculations were done for incompressible flow of a Newtonian fluid with developing momentum and thermal boundary layers under uniform and discrete heating conditions. It was found that the local Nusselt number near a protrusion changes significantly with the variations of Reynolds number, height, width, and distance between protrusions, and the distribution of discrete heat sources. The results presented in the paper demonstrate that protrusions can be used advantageously for the enhancement of local heat transfer whereas the global performance may be enhanced or diminished based on the channel geometry.

Keywords: Convection, microtube, microchannel, protrusion, discrete heating.
\end{abstract}

\section{INTRODUCTION}

There has been a remarkable growth in the field of Micro Electro Mechanical Systems (MEMS) over the last twenty five years. Experimental and theoretical studies in the literature have shown that a very high rate of heat and mass transfer in microchannels is the key to the extreme technologies being developed. As a matter of fact, the increase in power dissipation of electrical circuits has led to the usage of different geometries, different materials and different coolants as substrates and working fluids to effectively remove the generated heat. This paper explores the steady state heat transfer characteristics in circular microtubes and two-dimensional microchannels with protrusions of various shapes and sizes in the flow field.

A review of experimental data on microchannels has been presented by Morini (2004) and a review of micro-fabrication techniques has been presented by Kandlikar and Grande (2003). Although a large pool of experimental data for both pressure drop and Nusselt number are available, a complete understanding of convection in a microtube or microchannel is still an open problem. A major issue that received considerable attention in recent literature is whether the continuum/classical model (the conventional Navier-Stokes equations and the conventional energy equation) are valid at the microscale. Adams et al. (1998) reported experimental data for turbulent, forced convection of water in circular microtubes with diameters of 0.76 and $1.09 \mathrm{~mm}$. They noted that the classical correlations for Nusselt number under-predicted the measured values and they proposed a specialized correlation. More recently, a similar experiment was performed by Owhaib and Palm (2004) in which turbulent forced convection of R$134 \mathrm{a}$ was investigated in a single microtube $(0.8,1.2$, or $1.7 \mathrm{~mm}$ internal diameter). Their results showed good agreement with classical correlations, while none of the specialized correlations including the one by Adams et al. (1998) agreed with the test data. Guo and Li (2003) argued that discrepancies between the experimental results for microchannels and the classical correlations might be due to measurement errors and should not be misinterpreted as being caused by novel phenomena at the microscale. Harms et al. (1999) carried out experiments on single phase forced convection in deep rectangular microchannels. Two configurations were tested, a single channel system and a multiple channel system. The experimentally obtained local Nusselt number agreed reasonably well with classical developing channel flow theory. Quadir et al. (2001) applied a finite element method to evaluate the performance of microchannel heat exchangers.

Liu et al. (2007) conducted a numerical investigation for fluid flow and heat transfer in microchannel cooling passages taking into account the effects of viscosity and thermal conductivity variations at low Reynolds numbers. It was found that the velocity fields were highly coupled with distribution of temperature and got distorted by variations of viscosity and thermal conductivity. Lelea et al. (2004) conducted experimental and numerical research on fluid flow and heat transfer in microtubes of diameters of $0.1,0.3$ and $0.5 \mathrm{~mm}$ for laminar flow with Reynolds numbers up to 800 and distilled water as the working fluid. They confirmed that the classical or conventional theories are applicable for water flow through microtubes when the entrance effects are considered.

Lee et al. (2004) conducted an experimental investigation to explore the validity of classical correlations based on conventional sized channels for predicting the thermal behavior in single-phase flow through rectangular microchannels. The microchannels considered ranged in width from $194 \mu \mathrm{m}$ to $534 \mu \mathrm{m}$, with the channel depth being nominally five times the width in each case. Each test piece was made of copper and contained ten microchannels in parallel. The experiments were conducted with water, with the Reynolds number ranging from approximately 300 to 3500 . Numerical predictions based on a classical, continuum approach was found to be in good agreement with experimental data. Shevade and Rahman (2007) investigated the velocity and temperature distributions in microchannels with rectangular and square cross sections during volumetric heat generation

\footnotetext{
*Corresponding Author: Tel: (813)974-5625, Fax: (813)974-3539, Email: mmrahman@usf.edu
} 
due to an imposed magnetic field. Gandolinium was used as the substrate material and water was used as the working fluid. Wang and Ding (2008) presented the experimental investigation of a complicated microchannel system that contained parallel longitudinal microchannels etched in a silicon substrate and transverse microchannels electroplated on a copper heat spreader. The addition of transverse channels resulted in an overall enhancement of heat transfer.

Chen and Wang (1998) experimentally examined the forced convective flow over two sequentially heated blocks mounted on one principal wall of a channel. In these experiments, the various block spacing were used and the Reynolds numbers were set at 1300 and 10000 which corresponded to the laminar and turbulent convective flow cases, respectively. Chang and Yang (2004) numerically investigated electrokinetically driven flow mixing in microchannels by incorporating pattered rectangular blocks to enhance species mixing. They found that the species mixing was enhanced by creating a stronger diffusion effect due to the constriction in the bulk flow. They also showed that patterning heterogeneous upper surfaces on the rectangular blocks enhance species mixing. Korichi and Oufer (2005) investigated the effect of the presence of three blocks, two on the lower wall and one on the upper wall on laminar convective heat transfer. The effects of Reynolds number, block spacing and dimensions and solid to fluid thermal conductivity ratio were studied for a uniform heat flux through the blocks. They found that as the value of Reynolds number was increased, the heat removal rate from the obstacles also increased with a maximum heat removal around the obstacle corners. They also showed that the temperature difference between the three obstacles decreased with increase in Reynolds number. Croce and D'Agaro (2005) investigated the roughness effect on heat transfer and pressure loss in microscale tubes and channels using a finite element CFD code. Surface roughness was explicitly modeled through a set of randomly generated peaks along the ideal smooth surface. Different peak shapes and distributions were considered. They assumed a fully developed flow in their analysis. In a later study, Croce et al. (2007) modeled surface roughness in microchannel as a set of three-dimensional conical peaks. Different peak heights and distributions in transverse and streamwise directions were considered. They found that there is a remarkable effect of roughness on pressure drop but a weaker effect of it on Nusselt number. The performance was also found to depend strongly on the geometric details of the roughness elements.

Arora et al. (2007) investigated wall features that create stable disrupted flow and break the laminar boundary layer in a microchannel over a wide range of flow rates. Experiments with gas flow with and without wall features showed that heat transfer increase is $20-80 \%$ more compared to the pressure drop increase in the laminar regime. Xua et al. (2008) presented three-dimensional numerical simulations of conjugate heat transfer in conventional and interrupted microchannel heat sinks. The interrupted design consisted of shortened parallel microchannels and transverse microchambers. The periodic developing flow resulted in significant enhancement of heat transfer. Lee and Teo (2008) numerically studied the effects of slanted grooves on the microchannel wall. The heat transfer was found to increase up to $12 \%$ without incurring substantial additional pressure drop. Abouali and Baghernezhad (2010) numerically studied the effects of rectangular and arc shaped grooves on microchannel surfaces.

This paper presents a numerical analysis of fluid flow and heat transfer processes in a circular microtube and in a two-dimensional microchannel that have obstructions in the flow path due to protrusions from the wall. We take into consideration the wall thickness and study the effects of strategically applying heat flux at the location where the surface effects (protrusions) are located and then compare with cases where the heat flux is applied at locations away from the protrusion or uniformly over the entire channel or tube outer wall. Different protrusion shapes modeled are rectangular, triangular, and semicircular. For the rectangular one, the height and the width of the protrusions are varied from $5 \%$ to $10 \%$ of the diameter of the microtube. Also the effect of more than one protrusion in the flow path is investigated by placing three and five equally spaced protrusions in the flow. The objective is to come up with a detailed understanding of the conjugate heat transfer and the effects of protrusion dimensions, spacing between them, and flow rate on the variations of Nusselt number. The novelty of this research is to find the details of fluid flow and convective heat transfer around a protrusion in a microchannel or microtube that has not been explored in any previous study. It may be noted that results obtained in previous studies on turbulent fluid flow and heat transfer in large size channels with obstructions particularly those done in relation to turbine blade cooling cannot be applied to the design of microchannel heat exchangers having laminar flow, because of significant difference in channel geometry as well as the fact that the flow pattern around a protrusion is quite different for laminar and turbulent flow regimes. The results presented here quantitatively demonstrate the effects of all related parameters.

\section{ANALYSIS AND COMPUTATION}

A schematic diagram of the microtube or microchannel is shown in figure 1(a). The $y-z$ axes refers to the Cartesian coordinate system used for the analysis of flow and heat transfer in a two-dimensional microchannel whereas the r-z axes refer to the cylindrical coordinate system used for the analysis of axi-symmetric flow and heat transfer in a microtube. The length of the channel or tube is divided into five sections and heat is supplied in three different configurations as shown in figure 1(a). In case I all sections are heated, in case II Sections 1, 3, and 5 are heated and in case III sections 2 and 4 are heated. The total length of the tube or channel is " $\mathrm{L}$ " and its wall thickness is " $\mathrm{t}$ ". Heat is applied to the outer surface of the channel or tube and two-dimensional protrusions of height "e" and length " $b$ " are present at the inner surface. In case of semi-circular shaped protrusion, the length is "bc" which is twice of "e". In case of multiple protrusions, they are equally spaced around the center protrusion with a spacing "s".

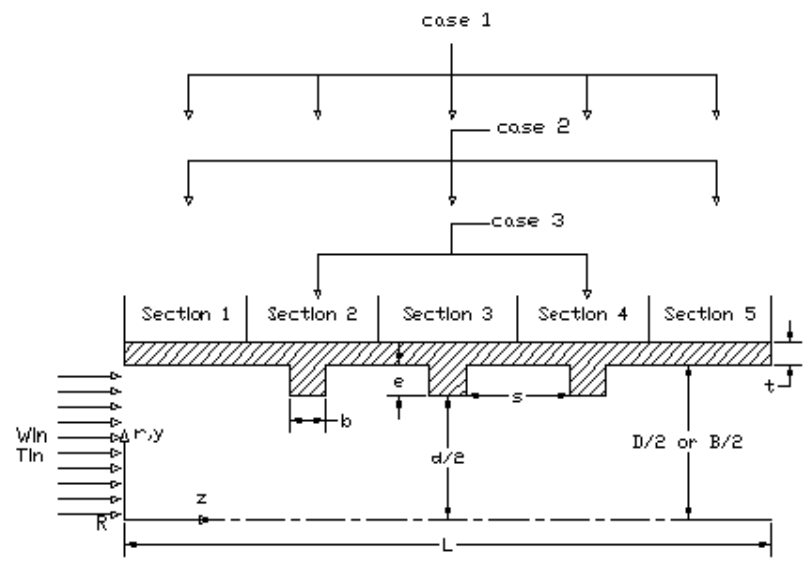

(a)

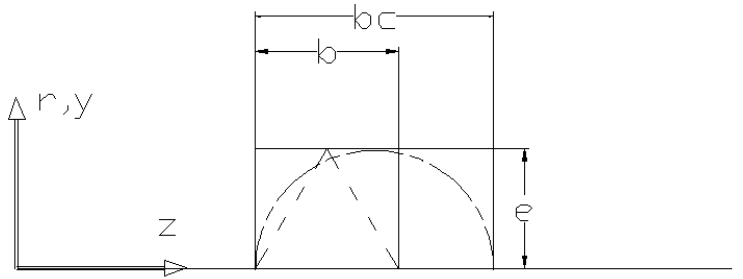

(b)

Fig. 1 Schematic diagram of the physical problem: (a) microchannel (microtube) cross-section; (b) Enlarged view of various shapes of the protrusions used. 
Figure 1(b) shows the various geometries of the protrusions investigated. The liquid coolant enters the micro-tube with a uniform velocity $\mathrm{w}_{\text {in }}$ and uniform temperature $\mathrm{T}_{\mathrm{in}}$. The flow is assumed to be incompressible, laminar, and steady. The applicable equations for the conservation of mass, momentum, and energy in the fluid region are (Kays et al., 2005),

$$
\begin{aligned}
& \nabla \cdot(\rho \vec{V})=0 \\
& \rho(\vec{V} \cdot \nabla) \vec{V}=-\nabla P+\mu \nabla^{2} \vec{V} \\
& \rho C_{p}(\vec{V} \cdot \nabla) T_{f}=\nabla \cdot k \nabla T_{f}
\end{aligned}
$$

Assuming constant thermal conductivity, the energy conservation equation in the solid structure is (Özisik, 1993),

$$
\nabla^{2} T_{s}=0
$$

The boundary conditions for the fluid flow in a microtube or a twodimensional microchannel are:

At $\mathrm{z}=0,0 \leq \mathrm{r}<\mathrm{D} / 2$ or $0 \leq \mathrm{y}<\mathrm{B} / 2$ :

$$
\mathrm{v}_{\mathrm{r}}=0 \text { or } \mathrm{v}=0, \mathrm{w}=\mathrm{w}_{\text {in }}, \mathrm{T}=\mathrm{T}_{\text {in }}
$$

At $\mathrm{z}=\mathrm{L}, 0 \leq \mathrm{r}<\mathrm{D} / 2$ or $0 \leq \mathrm{y}<\mathrm{B} / 2$ : $\mathrm{P}=0$

At $0 \leq \mathrm{z} \leq \mathrm{L}, \mathrm{r}=0$ or $\mathrm{y}=0$ :

$\mathrm{v}_{\mathrm{r}}=0, \frac{\partial w}{\partial r}=0, \frac{\partial T_{f}}{\partial r}=0$ or $\mathrm{v}=0, \frac{\partial w}{\partial y}=0, \frac{\partial T_{f}}{\partial y}=0$

The boundary conditions for conduction in the solid region are:

At $\mathrm{z}=0, \mathrm{D} / 2<\mathrm{r}<\mathrm{D} / 2+\mathrm{t}$ or $\mathrm{B} / 2<\mathrm{y}<\mathrm{B} / 2+\mathrm{t}: \frac{\partial T_{s}}{\partial z}=0$

At $\mathrm{z}=\mathrm{L}, \mathrm{D} / 2<\mathrm{r}<\mathrm{D} / 2+\mathrm{t}$ or $\mathrm{B} / 2<\mathrm{y}<\mathrm{B} / 2+\mathrm{t}: \frac{\partial T_{s}}{\partial z}=0$

At $0 \leq \mathrm{z} \leq \mathrm{L}, \mathrm{r}=\mathrm{D} / 2+\mathrm{t}$ or $\mathrm{y}=\mathrm{B} / 2+\mathrm{t}$ :

$\frac{\partial T_{s}}{\partial r}=q_{w} \quad$ or $\quad \frac{\partial T_{s}}{\partial y}=q_{w}$

At the solid-fluid interface (tube or channel inner wall or on the surfaces of the protrusions:

$\mathrm{T}_{\mathrm{f}}=\mathrm{T}_{\mathrm{s}}, k_{f} \frac{\partial T_{f}}{\partial n}=k_{s} \frac{\partial T_{s}}{\partial n}$

where $\mathrm{n}$ is the direction perpendicular to the surface.

The governing equations along with the boundary conditions were solved using the Galerkin finite element method. Four node quadrilateral elements were used. The aspect ratio (the ratio of the element lengths in the $\mathrm{z}$-direction to the $\mathrm{r}$ - or $\mathrm{y}$-direction) was maintained greater than 1 and less than 8 . In each element, the velocity, pressure, and temperature fields were approximated which led to a set of equations that defined the continuum. The Newton-Raphson algorithm was used to solve the nonlinear system of discretized equations. An iterative procedure was used to arrive at the solution for the velocity and temperature fields. The solution was considered converged when the field values became practically constant and the relative change from one iteration to the next reduced below $10 \mathrm{E}-6$.

The distribution of cells in the computational domain was determined from a series of tests with different number of elements. Results for the variation of local Nusselt number were generated for two cases: the first one being a microtube containing a rectangular protrusion of $\mathrm{e}=0.05 \mathrm{D}$, and the other for the two-dimensional microchannel with a rectangular protrusion of $e=0.05 \mathrm{~B}$ using different mesh sizes in each case. The numbers of elements were 150x8 (150 in the axial direction $\times 8$ in the radial/vertical direction), 300x16, 450x24 and $600 \times 32$. The results of these simulations showed that for both cases, grid independence is attained if $450 \times 24$ mesh is used for simulation. Therefore, the results reported in this paper used $450 \times 24$ elements in axial and radial/vertical directions.

\section{RESULTS AND DISCUSSION}

We considered three different heating cases for both microtube and twodimensional microchannel. In case I, a constant heat flux was applied to all the sections resulting in uniform heating. In case II, sections 1, 3, and 5 were heated. Section 3 is the part of the tube where the protrusion is present (for the single protrusion case). In this case, sections 2 and 4 were not heated (insulated). In case III, sections 2 and 4 were supplied with a constant heat flux and sections 1,3 and 5 were kept insulated. Magnitude of heat flux was adjusted for each of the discrete heating cases in order to make the same total heat input for all the cases. The fluid entering the microtube or microchannel was maintained at $\mathrm{T}_{\mathrm{in}}=$ $20^{\circ} \mathrm{C}$. The diameter of the microtube (D) or the distance between walls in the two-dimensional microchannel (B) was also kept at a constant value of $700 \mu \mathrm{m}$. The inlet velocity $\left(\mathrm{w}_{\text {in }}\right)$ was varied to provide a range of Reynolds number from 500 to 1500 . The height of the protrusion was varied between $e=0.05 \mathrm{D}$ to $\mathrm{e}=0.1 \mathrm{D}$ and the width was varied between $b=0.05 \mathrm{D}$ and $\mathrm{b}=0.1 \mathrm{D}$ for the rectangular protrusion. For the triangular protrusion, $\mathrm{e}=0.05 \mathrm{D}$ and $\mathrm{b}=0.05 \mathrm{D}$ were used. The semicircular protrusion had a radius of $0.05 \mathrm{D}$. A length of $\mathrm{L}=1 \mathrm{~cm}$ was used. The wall thickness was varied in the range $t=100-700 \mu \mathrm{m}$. Aluminum was used as the solid material. Its properties were assumed to remain constant over the working temperature range. Water and R-134a were used as working fluids. The properties of these fluids were correlated according to the following equations. For water between $293 \mathrm{~K}<\mathrm{T}<$ $400 \mathrm{~K} ; \mathrm{Cp}_{\mathrm{f}}=9.5 \times 10^{-3} \mathrm{~T}^{2}-5.9299 \mathrm{~T}+5098.1 ; \mathrm{k}_{\mathrm{f}}=-7.0 \times 10^{-6} \mathrm{~T}^{2}+$ $5.8 \times 10^{-3} \mathrm{~T}-0.4765 ; \rho_{\mathrm{f}}=-2.7 \times 10^{-3} \mathrm{~T}^{2}+1.3104 \mathrm{~T}+848.07 ;$ and $\ln \left(\mu_{\mathrm{f}}\right)=$ $-3.27017-0.0131 \mathrm{~T}$. For R-134a between $230 \mathrm{~K}<\mathrm{T} 360 \mathrm{~K} ; \mathrm{Cp}_{\mathrm{f}}=$ $1 \times 10^{-4} \mathrm{~T}^{2}-0.0493 \mathrm{~T}+7.6462 ; \mathrm{k}_{\mathrm{f}}=0.0003 \mathrm{~T}^{2}-0.5937 \mathrm{~T}+234.62 ; \quad \rho_{\mathrm{f}}=$ $-0.0224 \mathrm{~T}^{2}+9.0255 \mathrm{~T}+5.18 .72 ; \ln \left(\mu_{\mathrm{f}}\right)=-0.014217 \mathrm{~T}+4.880646$.

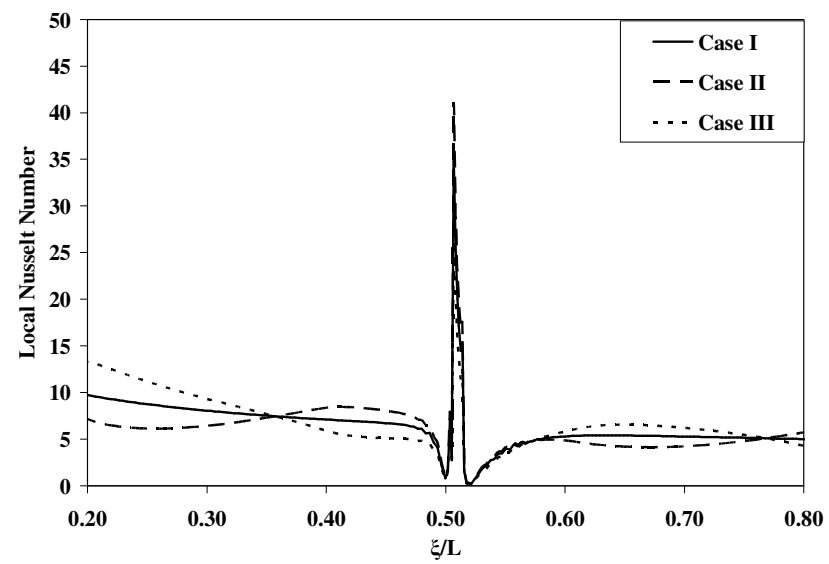

(a)

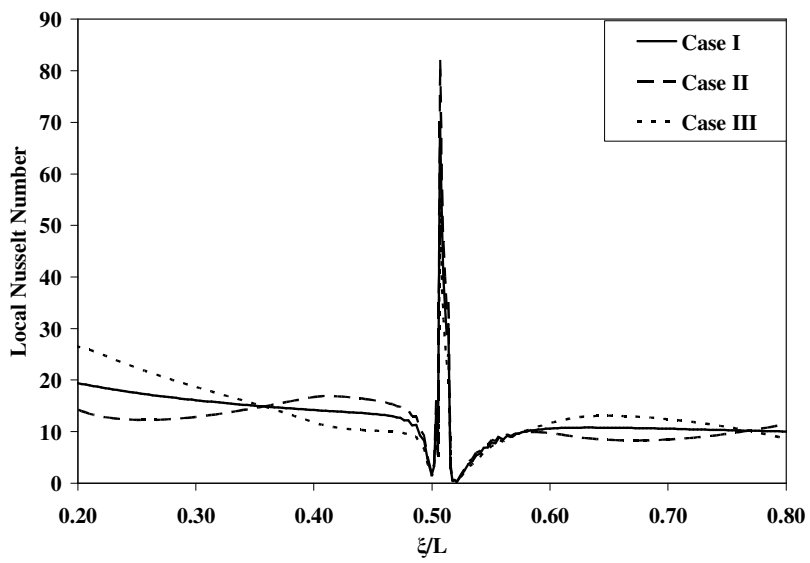

(b)

Fig. 2 Local Nusselt number variation for different heat input scenario $(\mathrm{Re}=500)$ : (a) Microtube, (b) Two-dimensional microchannel. 
Figure 2 compares local Nusselt number variation along the length of the microchannel and microtube with rectangular protrusion for the three heating cases. In figure 2(a), we see that in heating case I, where all the sections of the microtube are heated, has a gradual decrease in Nusselt number as the flow moves downstream until the protrusion is encountered. At the location where the protrusion is present, there is a rapid fall in the value of the local Nusselt number as the flow is interrupted by the presence of the protrusion and the fluid moves away from the heated wall to go over the protrusion. At the leading edge of the protrusion, there is a gradual increase in local Nusselt number along the front wall. At the top front corner, the value of local Nusselt number is the highest because the momentum and the thermal boundary layers begin to form again using the corner of the protrusion as the leading edge. As the boundary layer thickness increases, we can see a gradual decrease of local Nusselt number until the flow reaches the trailing corner. Then at the rear wall of the protrusion, we observe a gradual fall in local Nusselt number due to expansion of the flow and associated recirculation. Starting with the bottom trailing edge of the protrusion, Nusselt number gradually increases downstream in the recirculating region following the protrusion. Then the local Nusselt number value recovers to the trend followed by a smooth microtube.

In heating case II, the value of local Nusselt number dips at $\xi / \mathrm{L}=0.2$ because the section from $\xi / \mathrm{L}=0.2$ and $\xi / \mathrm{L}=0.4$ is not heated and then the curve loops up as the heat flux is applied at section 3 i.e. $\xi / \mathrm{L}=0.4$ to $\xi / \mathrm{L}=0.6$. Section 3 is where the protrusion is located and we see a similar behavior in the variation of local Nusselt as seen in case I. In section 4, the value of Nusselt number goes down as we don't have heating at this section. The value of Nusselt number goes up again in section 5. At the front top corner of the protrusion, the jump in the value of local Nusselt number in this case is higher compared to case I. This is due to localized heating with higher heat flux at section 3 where the protrusion is present. In case III, as the section 2 is heated, the Nusselt number is more at $\xi / \mathrm{L}=0.2$ and then falls a little at $\xi / \mathrm{L}=0.4$. At the protrusion the values of Nusselt number is lower than that of cases I and II, but follows the same trend in the variation of local Nusselt number. We observe that the value of Nusselt number is more for this case in section 4 due to the fact that a localized heating is done at that section. In section 5 which starts from $\xi / \mathrm{L}=0.8$ we see that the value of Nusselt number goes down as there is no heat flux being applied at that section.

Figure 2 (b) shows the variation of local Nusselt number for twodimensional microchannel for the three heating cases. The trend of the local Nusselt number variation is exactly identical to the trend observed in the microtube; the only difference is that the value of local Nusselt number is approximately twice that of the microtube. This is because the hydraulic diameter used in the calculation of Nusselt number is $2 \mathrm{~B}$ for the case of two-dimensional microchannel, whereas it is the tube diameter $\mathrm{D}$ for the case of microtube. The heat transfer coefficients for the two cases are on the same order of magnitude. It may be also noted in Figure 2 that local Nusselt number decreases to a very small value (but not zero) at the trailing end of the protrusion. This is because of low rate of convective heat transfer due to stagnant fluid at the trailing corner of the protrusion.

Figure 3 shows the variation of local Nusselt number along various geometries of the protrusions such as rectangular, triangular, and semicircular protrusions and compared those with the smooth microtube case for all the three heating cases. Figure 3(a) shows the local Nusselt number variation for various shapes for heating case I where the heat flux is applied uniformly along the outer wall of the microtube. Here the rectangular and the triangular protrusions start at $\xi / \mathrm{L}=0.5$ and end at $\xi / \mathrm{L}=0.507$ and the semicircular protrusion starts at $\xi / \mathrm{L}=0.5$ and ends at $\xi / \mathrm{L}=0.51$. In the protrusions of rectangular and triangular shapes we observe that there is a drop in the local value of Nusselt number before the beginning of the protrusion because the flow is interrupted by the presence of the protrusion and the fluid moves away from the heated wall to go over the protrusion. This creates

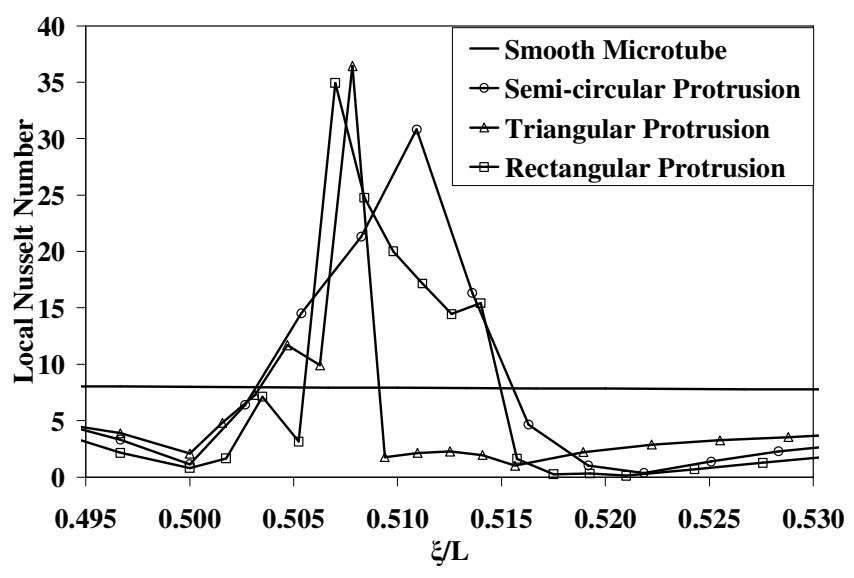

(a)

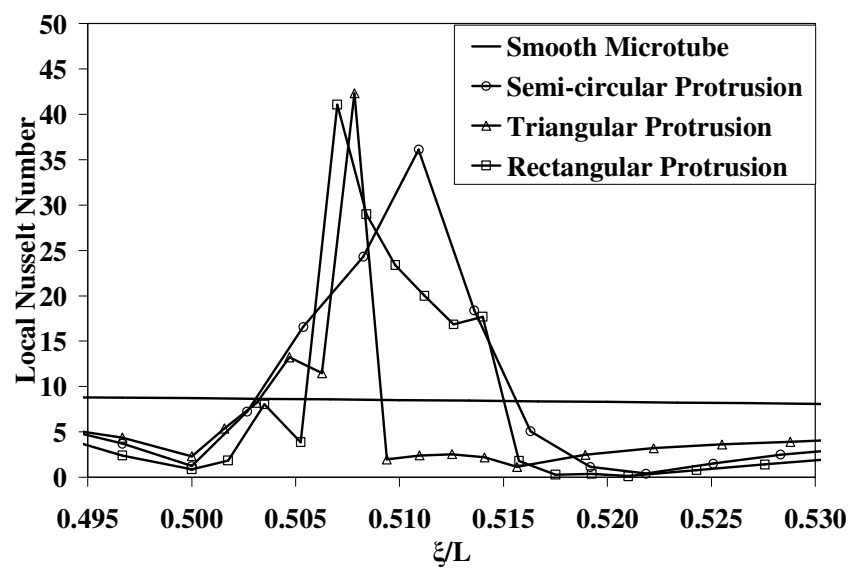

(b)

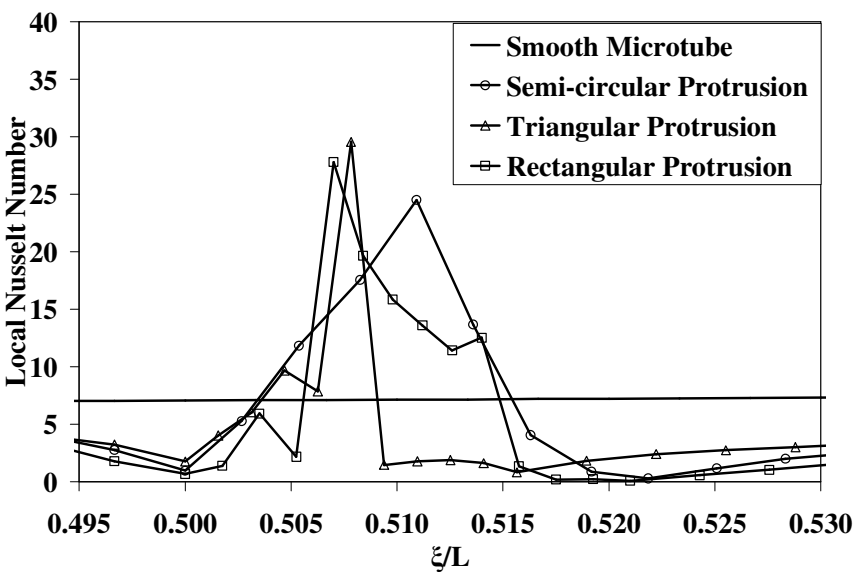

(c)

Fig. 3 Local Nusselt number along streamwise direction for rectangular, triangular and semicircular protrusions in a microtube ( $\mathrm{Re}=500$ ): (a) Heating case I, (b) Heating case II, (c) Heating case III.

a small recirculation region before the protrusion where the heat transfer rate falls below the smooth microchannel. For the rectangular shaped protrusion, there is a gradual increase of local Nusselt number along the front wall followed by an abrupt increase as we reach the top wall of the protrusion. At the top front corner, the value of local Nusselt number is the highest because the momentum and the thermal boundary layers begin to form again using the corner of the protrusion as the leading edge. As the boundary layer thickness increases we can see a gradual decrease of Nusselt number until the flow reaches the trailing 
corner. Then at the rear wall of the protrusion, we observe a gradual fall in local Nusselt number due to expansion of the flow and associated recirculation. Starting with the bottom trailing edge of the protrusion, Nusselt number gradually increases downstream in the recirculating region following the protrusion.

In the case of the triangular shaped protrusion we see a steady increase in the value of local Nusselt number as the cross-sectional area of the flow decreases and local fluid velocity increases in the direction of the flow. A peak is seen at the vertex of the triangle. At the downstream side of the triangle, the Nusselt number first decreases abruptly and then gradually. The sharp corner directs the main flow to a larger distance downstream and the rear wall of the protrusion is essentially occupied by the recirculating flow. A minimum is seen at a location just downstream from the protrusion. Further downstream, the Nusselt number increases gradually. For the case involving the semicircular protrusion, the rise and fall of local Nusselt number along the protrusion is quite gradual showing much smoother transition compared to the other two shapes of the protrusion. The maximum Nusselt number is seen at the tip of the semi-circle where the flow area is the minimum. When the inlet velocity of the fluid was increased to obtain higher Reynolds numbers, we saw an increase in the magnitude of the Nusselt number at the location of the protrusion. The distribution pattern, however, remained the same.

Figure 3(b) shows the variation of local Nusselt number for heating case II in which the heat flux is applied at sections 1, 3, and 5 and the protrusion is located at section 3 . Here we see that the value of local Nusselt number jump at all the three protrusion shapes is higher compared to the other two heating cases. This is again due to fact that the heat flux is discretely applied at the protrusion and in the heated portion of the tube immediately preceding the protrusion resulting in the development of a new thermal boundary layer at the start of section 3. Figure 3(c) shows the local Nusselt number variation for the third heating case where the heat flux is applied at sections away from the location of the protrusion, i.e. sections 2 and 4 . Here the peak Nusselt number came out to be lower because of lower Nusselt number compared to other cases immediately before the protrusion. It may be also noted that heat is transferred by axial conduction in the tube and eventually dissipated by convection from the inner walls of the tube and the protrusion.

The effects of various sizes of the protrusion for the three heating cases can again be interpreted by comparison of local Nusselt number. Here, we varied two parameters height "e" and width "b" of the protrusion: first the height of the protrusion "e" was varied (from 0.05 to 0.1 times "D") keeping the width "b" constant, next the height "e" was kept constant and the width "b" was varied (from 0.05 to 0.1 times "D"). It was thought that a protrusion height of 5-10\% of channel diameter will be adequate to enhance the local heat transfer rate at the protrusion without blocking the flow too much that may adversely affect the pumping power.

Figure 4(a) shows the variation of local Nusselt number along the streamwise direction for a constant width of $b / D=0.05$ for the heating case I where a constant heat flux is applied all along the length of the tube. We see that as the height of the protrusion increases the value of local Nusselt number also increases. The highest Nusselt number for each case is seen at the top front corner. This is due to the formation of both thermal and momentum boundary layers at the top of the protrusion with the front top corner as the leading edge. With the increase of protrusion height i.e. "e/D", the flow cross-sectional area reduces and causes a larger velocity of flow in the area covered by the protrusion. This enhances the local convection heat transfer coefficient. A larger "e/D" however, means a larger jump for the flow and therefore a longer recirculation region before and after the protrusion. In those areas, Nusselt number decreases with increase of "e/D".

Figure 4(b) shows the streamwise local Nusselt number variation for the heating case II where sections 1,3 , and 5 are heated and the protrusion is located in the middle of the 3rd section. Here again we observe similar local Nusselt number variation as seen in heating case I but the value of the maximum Nusselt number is greater than the previous case. Figure 4(c) shows the variation of local Nusselt number for the heating case III in which the heat flux is not applied to the section where the protrusion is located. Here the jump in the value of local Nusselt number of each height is lesser than those in cases I and II, due to the fact that Nusselt number starts up with a lower value as the flow approaches the protrusion since no heat flux is being applied at section 3 where the protrusion is located.

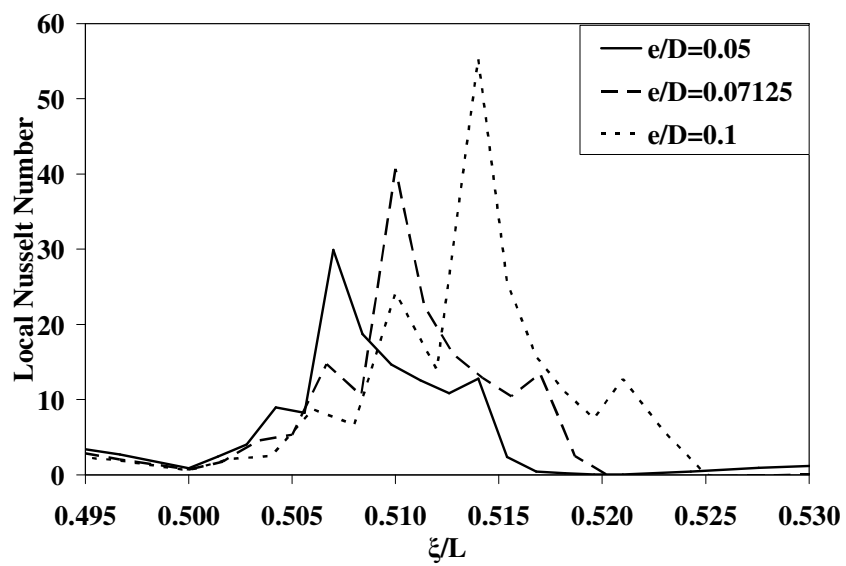

(a)

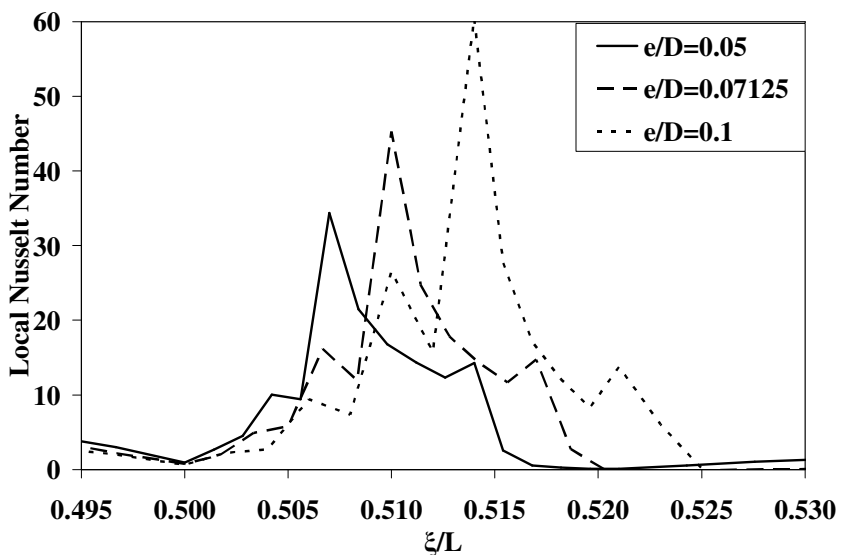

(b)

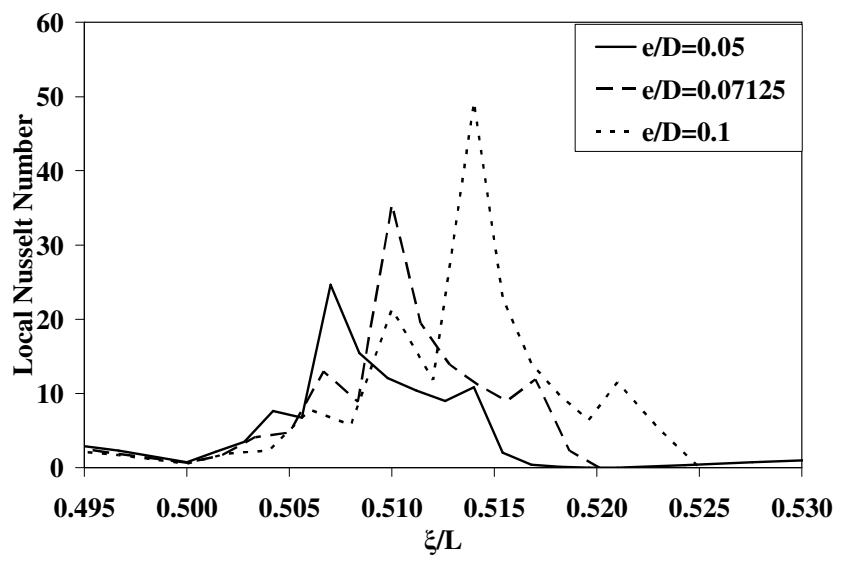

(c)

Fig. 4 Local Nusselt number when varying height 'e' keeping 'b' constant for a rectangular protrusion in a microtube $(\mathrm{Re}=500)$ : (a) Heating case I, (b) Heating case II, (c) Heating case III. 


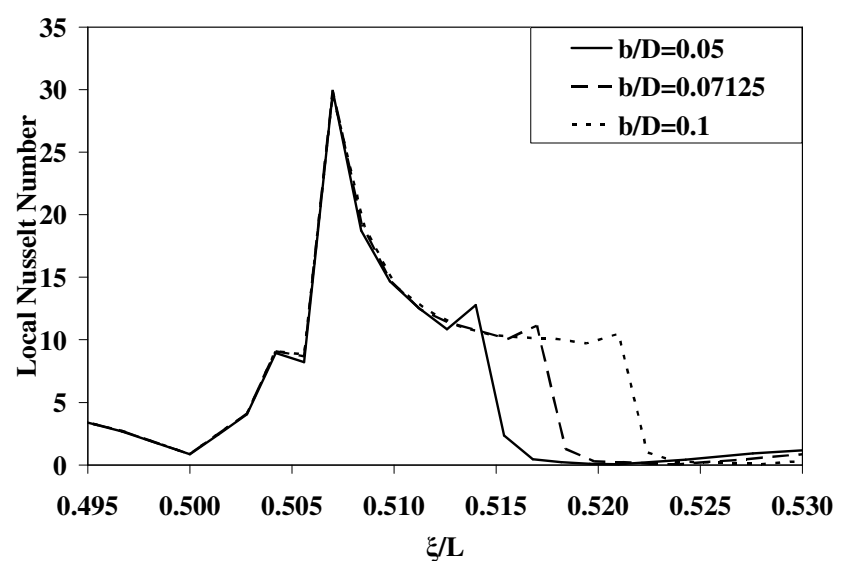

(a)

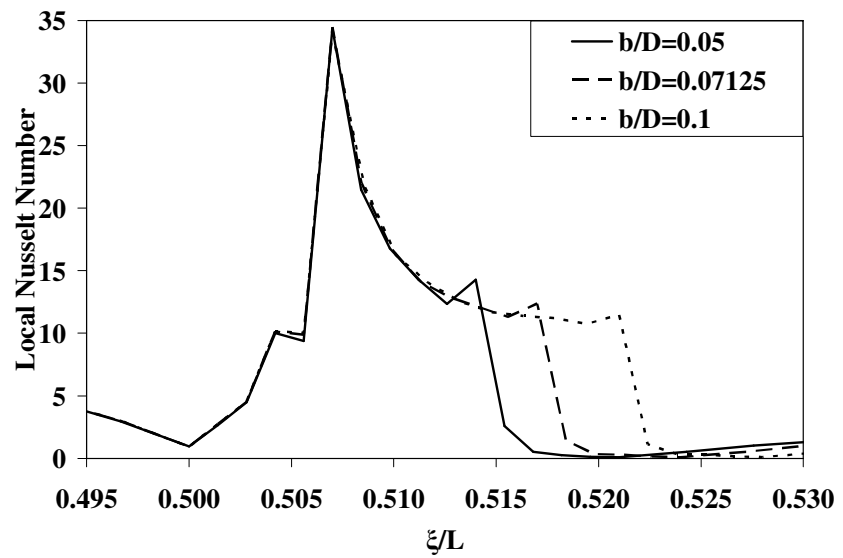

(b)

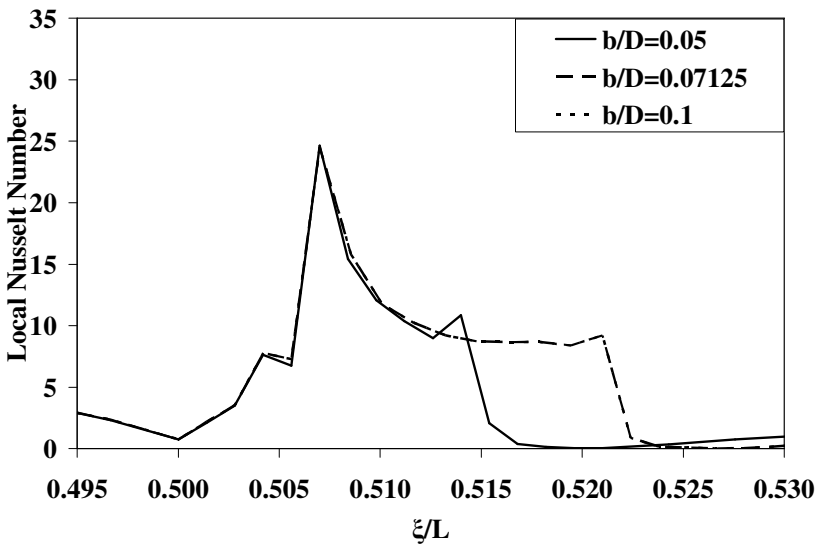

(c)

Fig. 5 Local Nusselt number when varying width ' $b$ ' keeping ' $e$ ' constant for a rectangular protrusion in a microtube $(\mathrm{Re}=500)$ : (a) Heating case I, (b) Heating case II, (c) Heating case III.

Now the height i.e. "e/D" is kept constant and the width i.e. "b/D" of the protrusion is varied and the variation of local Nusselt number is shown in figure 5 for all three heating cases. Figure 5(a) shows the variation of local Nusselt Number for the heating case I where the heat flux is applied uniformly along the length of the microtube. Here, we can notice that the value of local Nusselt number remains the same for all three protrusions until the trailing edge of the protrusion is approached. Different values in the recirculation region downstream of the protrusion are primarily due to different locations for the start of the new thermal boundary layer. Figures 5(b) and 5(c) respectively present the variations of local Nusselt number along the streamwise direction for the heating cases II and III. The trend in the variation of local Nusselt number in these figures is the same as that in Figure 5(a) but the values are different. The highest value of local Nusselt number is obtained for the heating case II because there is discrete heating with higher heat flux at the section of the microtube where the protrusion is located.

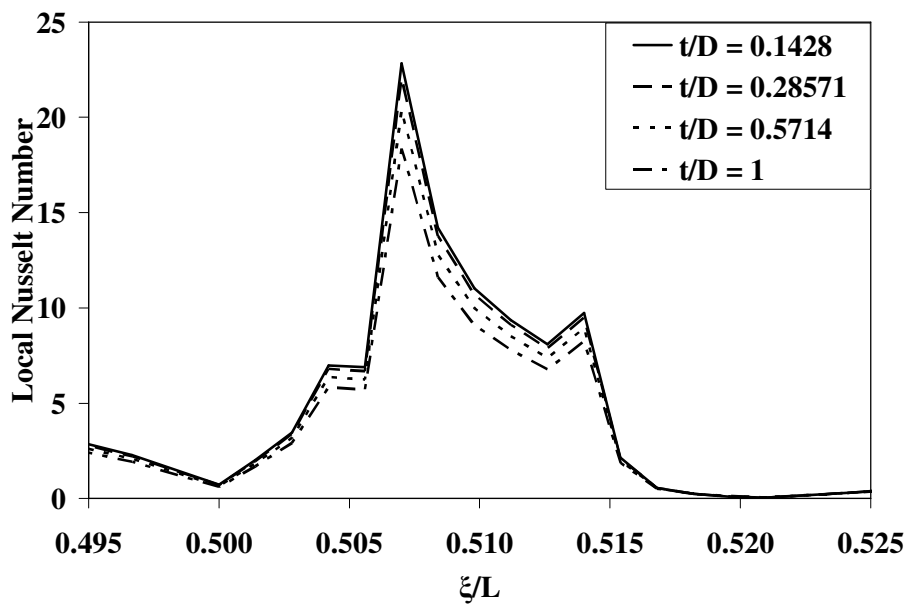

(a) Heating Case I.

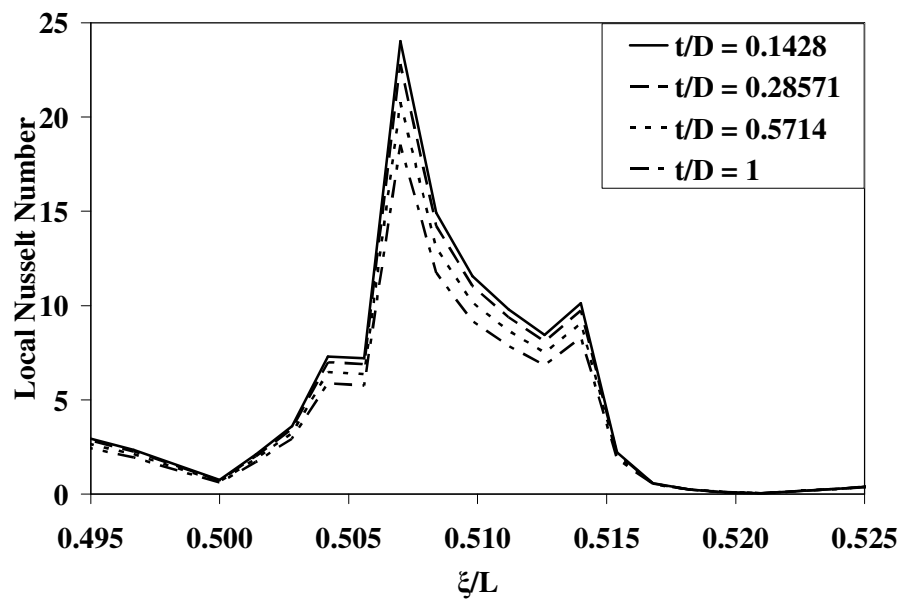

(b) Heating Case II.

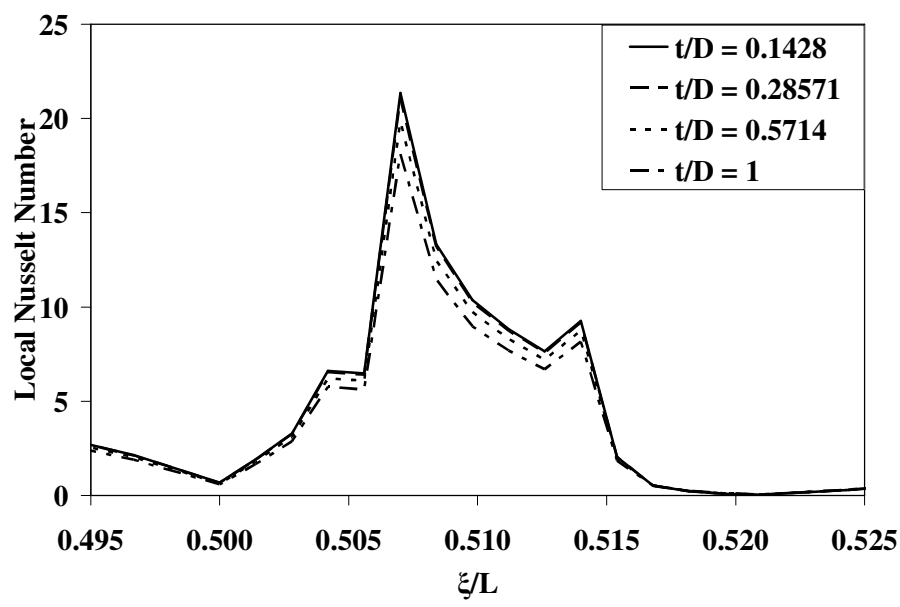

(c) Heating Case III.

Fig. 6 Local Nusselt number variation with wall thickness in aluminum microtubes with refrigerant R-134a as the working fluid. 
All the above results obtained were for the wall thickness of 100 $\mu \mathrm{m}$ i.e. $\mathrm{t} / \mathrm{D}=0.1428$; now we can increase the wall thickness to $200 \mu \mathrm{m}$ $(\mathrm{t} / \mathrm{D}=0.28571), 400 \mu \mathrm{m}(\mathrm{t} / \mathrm{D}=0.5714)$ and $700 \mu \mathrm{m}(\mathrm{t} / \mathrm{D}=1)$. Figures 6 (a), (b), and (c) show the variation of local Nusselt number for different wall thicknesses used in the circular microtube with a rectangular protrusion at the 3rd section, for the three heating cases.

Figure 6 (a) shows the variation of local Nusselt number for case I where the heat flux is applied uniformly all along the protrusion. We observe a steady decrease in the value of jump in Nusselt number at the start of the protrusion as the wall thickness increases. This is due of the smoothening effect of the wall of the microtube because as the wall thickness is increased the distance the heat has to travel to the inner wall is increased and also the heat gets more evenly conducted within the solid medium, thus causing the reduced temperature gradient and in turn the reduced local Nusselt number value. Figure 6 (b) shows the variation of local Nusselt number at the protrusion for various thicknesses for case II where the heat flux is applied at the protrusion. Here we see that there is a similar decrease in the jump of value of Nusselt number at the protrusion but the maximum values reached for this case is higher than the values seen in figure 6 (a) for the first case. In figure 6 (c) we see the local Nusselt number variation at the protrusions for various thicknesses for case III, where no heat flux is being applied at the protrusion. In this case the distance traveled by the heat is larger which causes the temperature gradient at the inner wall i.e. the solid-fluid interface to be lower causing the reduction in the value of local Nusselt number. Here, we also observe that the decrease in the value of local Nusselt number with thickness is smaller compared to the other two cases.

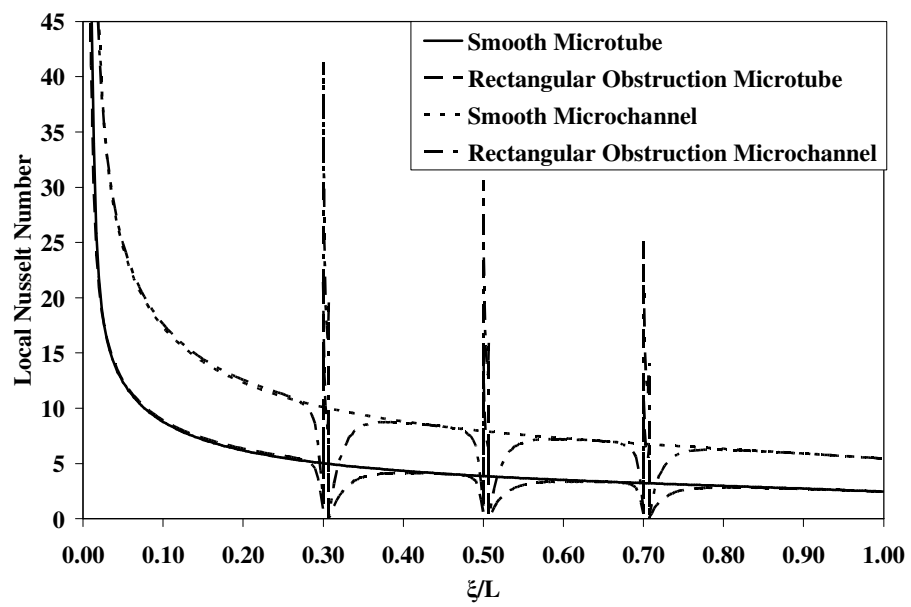

Fig. 7 Local Nusselt number comparison for aluminum microchannels and microtubes with three protrusions using water as the working fluid.

Till now we have seen the effects of a single protrusion on the variation of local Nusselt number. Now we consider more than one protrusion in the flow path. For this we consider two configurations, the first configuration consists of three protrusions and the second configuration consist of five protrusions in both cases equally spaced along the length of the microtube or microchannel. Figure 7 presents the results for the three equally spaced protrusions in the flow path for both the microtube and microchannel and compared those with the smooth microtube and microchannel for the case where a uniform heat flux is applied all along the length of the microtube or microchannel. It can be observed that the local Nusselt number again peaks at the top front corner of the protrusion similar to case of the single protrusion. But the highest value of local Nusselt number at the protrusion goes on decreasing along the length even though the protrusions are of the same height and width. This is because of the larger bulk fluid temperature as the flow moves downstream. The local heat transfer rate is intimately related to the wall to fluid temperature difference. As the wall to fluid temperature difference drops, the local heat transfer coefficient or Nusselt number drops. Another interesting observation from figure 7 is that after each protrusion the local Nusselt number recovers to the distribution shown by smooth tube or channel. Therefore, if sufficient distance is provided between protrusions, the local Nusselt number over a good portion of the tube or channel that are away from restricted areas will not be affected by the presence of the protrusion or there is no significant history effect of the flow. It suggests that protrusions can be conveniently used to trigger local enhancement without greatly affecting the overall heat transfer pattern. Similar characteristics were seen in the case of the triangular and semi-circular protrusions.

Figure 8 presents the results for the second configuration containing five equally spaced protrusions. It can be observed that the local Nusselt number variation is similar to that of the three protrusion configuration, but the distance between the consecutive protrusions is smaller and hence the flow just stabilizes and the momentum and thermal boundary layers are not fully established in the region between protrusions before the flow is again disturbed. Hence we see that the local Nusselt number values do just catch up with the smooth microtube or microchannel values. Due to smaller distance between protrusions, the flow cannot recover before being disturbed by the subsequent protrusion. Therefore, the number of protrusions and spacing between them have very important roles in controlling the overall heat transfer characteristics of the system.

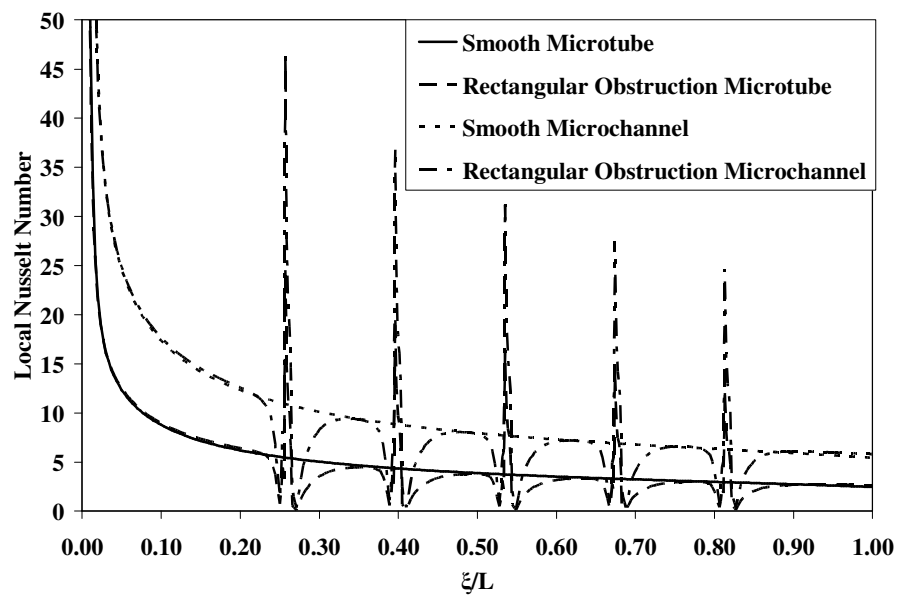

Fig. 8 Local Nusselt number comparison for aluminum microchannels and microtubes with five protrusions using water as the working fluid.

Until now we studied the local Nusselt number variation for microchannels and microtubes with protrusions. Average Nusselt number can be calculated by taking an area weighted average of all the local values of Nusselt number along the length of the microchannel or microtube. Figure 9 shows the average Nusselt number for different Reynolds numbers and shapes of protrusion for the heating case I in which the heat flux is applied uniformly all along the length of the tube. In figure 9(a), we find that a reduction in the global heat transfer rate for a microtube containing a protrusion when compared to a smooth microtube. This decrease is a function of both the shape of the protrusion and the Reynolds number. The actual shape of the protrusion has an effect on the numerical values of Nusselt number, but does not change the qualitative behavior. The decrease in the heat transfer coefficient is more for the rectangular shape. This can be explained as: the global Nusselt number is the surface area weighted average of values at the peaks (higher than the smooth microtube) and values at the valleys (lower than smooth microtube). The peaks cover a lower area (smaller radius) compared to the valley (higher radius). In addition, the peak happening at the protrusion covers a smaller length compared to the lengths covered by the two recirculating regions at the valley. 
Hence, the balance is shifted to a lower average Nusselt number. In Figure 9(b) we compare the average Nusselt number for various shapes of the protrusions in a two-dimensional microchannel with the smooth two-dimensional microchannel for Reynolds numbers varying from 500 to 1500 . Here we find an increase in the average Nusselt number for the channel containing the protrusion when compared to the smooth channel. This increase is again a function of both the shape of the protrusion and the Reynolds number. A rectangular protrusion provides the largest enhancement of average Nusselt number. It may be noted that all locations of local Nusselt number are now associated with the same area unlike the case of microtube and that results in an overall enhancement of average Nusselt number when a protrusion is present.

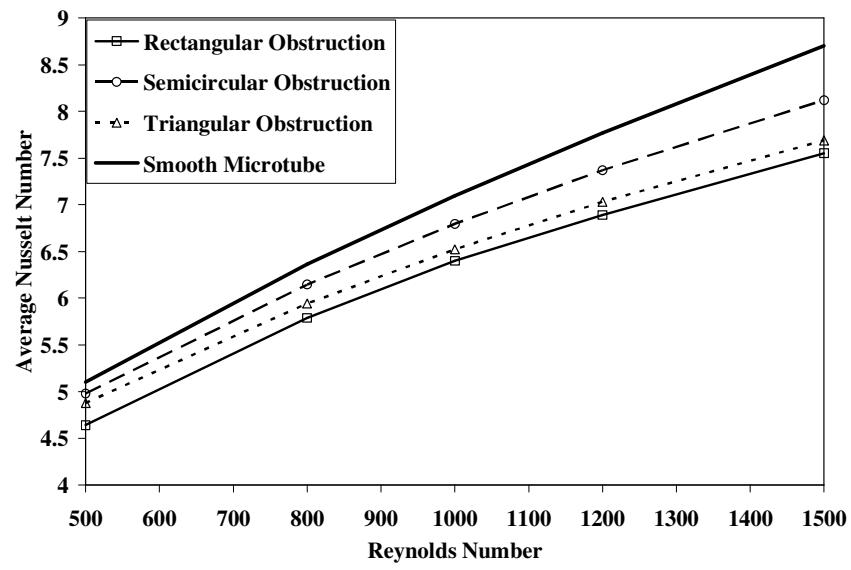

(a)

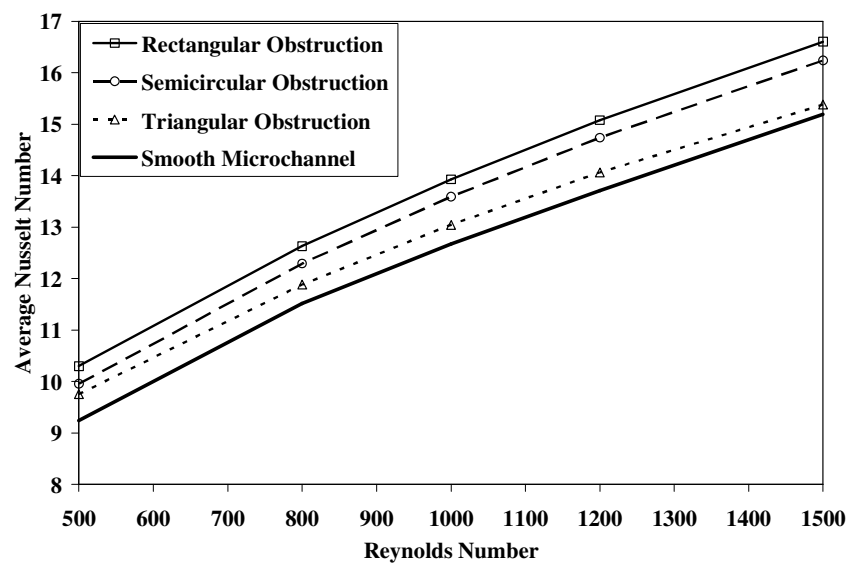

(b)

Fig. 9 Average Nusselt number for various protrusion shapes: (a) circular microtube; (b) two-dimensional microchannel.

In Figure 10(a) we see the variation of average Nusselt number for smooth microtube and the microtubes with one, three and five protrusions for heating case I. The smooth tube has the highest Nusselt number and the other three configurations have lesser average values. But in Figure 10(b) the smooth channel has the lowest Nusselt number when compared to the other three configurations. It can be noticed that 1-protrusion case has the highest enhancement compared to multiple protrusions in the flow path.

\section{CONCLUSIONS}

Effects of protrusions on the conjugate heat transfer in microtubes and microchannels were investigated. The Nusselt number is found to be sensitive to the shape and the size of the protrusion. For a rectangular protrusion, we noticed a sudden jump in local Nusselt number value due to the start of a new thermal boundary layer at the front corner of the protrusion. For other protrusion shapes, a gradual increase in Nusselt number along the protrusion happens until minimum flow area is reached and then a gradual decrease happens further downstream. When the height of the protrusion is increased, the peak value of local Nusselt number also increases. The trend of variation of local Nusselt number around the protrusion was the same for circular microtube and two-dimensional microchannel, but the values in the case of microchannel was significantly higher. In the circular microtube with protrusion case, we noticed a reduction in average Nusselt number when compared to the smooth tube. The single protrusion configuration has the lowest average Nusselt number value when compared to the three protrusion and the five protrusion configurations for the microtube. On the other hand, in the twodimensional microchannel case we noticed an increase in global value of Nusselt number when compared to smooth microchannel.

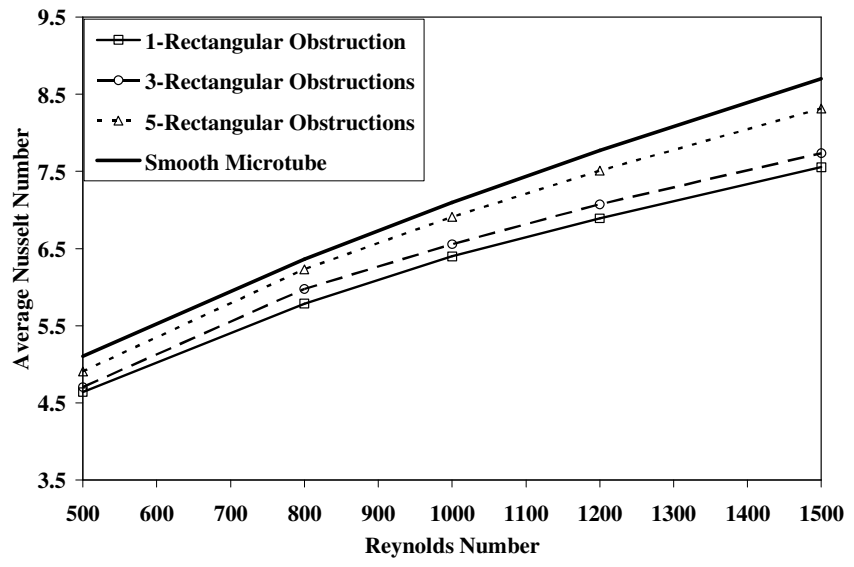

(a)

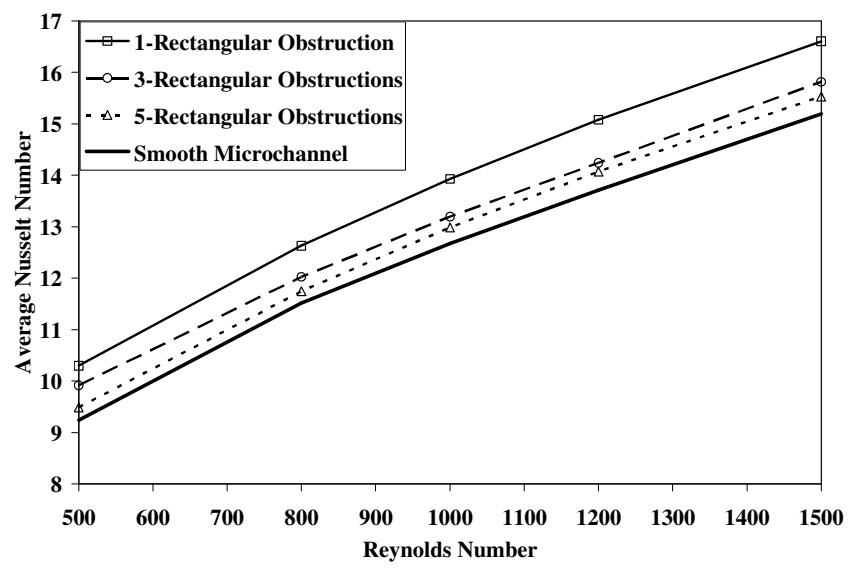

(b)

Fig. 10 Average Nusselt number for repeated protrusions: (a) circular microtube; (b) two-dimensional microchannel.

\section{NOMENCLATURE}

b Length of rectangular protrusion, $\mathrm{m}$

bc Length of semi-circular protrusion, $m$

B Height of two-dimensional microchannel, $\mathrm{m}$

$\mathrm{C}_{\mathrm{p}} \quad$ Specific heat, $\mathrm{J} / \mathrm{kg}-\mathrm{K}$

D Tube diameter, $\mathrm{m}$

d Diameter of the tube or height of the channel at the peak of the protrusion, $\mathrm{m}$

e Height of the protrusion, $m$

k Thermal conductivity, W/m.K

L Tube length, $m$ 
$\mathrm{Nu} \quad$ Local peripheral average Nusselt number, ( $\left.\mathrm{q}^{\prime}{ }_{\mathrm{w}} \mathrm{D}\right) /\left(\mathrm{k}\left(\mathrm{T}_{\mathrm{w}^{-}}\right.\right.$ $\left.\mathrm{T}_{\mathrm{b}}\right)$ )[tube], $\left(2 \mathrm{q}{ }_{\mathrm{w}} \mathrm{B}\right) /\left(\mathrm{k}\left(\mathrm{T}_{\mathrm{w}}-\mathrm{T}_{\mathrm{b}}\right)\right)$ [channel]

$\mathrm{Nu}_{\text {avg }} \quad$ Average Nusselt number for the entire tube or channel

$\mathrm{P} \quad$ Pressure, N/m $\mathrm{m}^{2}$

Re Reynolds number, $\left.\left(\mathrm{w}_{\text {in }} \mathrm{D}\right) / \mathrm{v}\right)\left[\right.$ tube], $\left.\left(\mathrm{w}_{\text {in }} \mathrm{B}\right) / \mathrm{v}\right)[$ channel]

$\mathrm{r} \quad$ Radial coordinate, $\mathrm{m}$

$\mathrm{s} \quad$ Spacing between two consecutive protrusions, $\mathrm{m}$

T Temperature, ${ }^{\circ} \mathrm{C}$

$\mathrm{t} \quad$ Wall thickness, $\mathrm{m}$

$\mathrm{v} \quad$ Velocity component in the y-direction

$\mathrm{v}_{\mathrm{r}} \quad$ Velocity component in the radial direction, $\mathrm{m} / \mathrm{s}$

$\vec{V} \quad$ Velocity vector, $\mathrm{m} / \mathrm{s}$

w Velocity component in the axial direction, $\mathrm{m} / \mathrm{s}$

y $\quad \mathrm{y}$-coordinate, $\mathrm{m}$

$\mathrm{z} \quad$ Axial coordinate, $\mathrm{m}$

Greek symbols

$\mu \quad$ Dynamic viscosity, $\mathrm{kg} / \mathrm{m}$ s

$\xi \quad$ Distance along the wall, $\mathrm{m}$

$\rho \quad$ Density, $\mathrm{kg} / \mathrm{m}^{3}$

Subscripts

b Bulk

f $\quad$ Fluid

in Inlet

s Solid

w Wall

\section{REFERENCES}

Abouali, O., Baghernezhad, N., 2010, "Numerical investigation of heat transfer enhancement in a microchannel with grooved surfaces," J. Heat Transfer, 132, 041005-1-041005-8. doi:10.1115/1.4000862

Adams, T.M., Abdel-Khalik, S.I., Jeter, S.M., Qureshi, Z. H., 1998, “An experimental investigation of single-phase forced convection in microchannels," Int. J. Heat Mass Transfer, 41, 851-857.

doi:10.1016/S0017-9310(97)00180-4

Arora, R., Tonkovich, A.L., Lamont, M.J., Yuschak, T., Silva, L., 2007, "Passive heat transfer enhancement in microchannels using wall features," Proceedings of the 5th International Conference on Nanochannels, Microchannels, and Minichannels, ASME, 461-468.

Chang, C-C., Yang, R-J., 2004, "Computational analysis of electrokinetically driven flow mixing in microchannels with patterned blocks," J. Micromechanics and Microengineering, 14, 550-558.

doi:10.1088/0960-1317/14/4/016

Chen, Y-M., Wang, K-C., 1998, "Experimental study on forced convective flow in a channel with heated blocks in tandem," Experimental Thermal and Fluid Science, 16, 286-298.

doi:10.1016/S0894-1777(97)10033-4

Croce, G., D'Agaro, P., 2005, "Numerical simulation of roughness effect on microchannel heat transfer and pressure drop in laminar flow," J. Phys. D: Appl. Phys., 38, 1518-1530.

doi:10.1088/0022-3727/38/10/005

Croce, G., D’Agaro, P., Nonino, C., 2007, “Three-dimensional roughness effect on microchannel heat transfer and pressure drop," Int. J. Heat Mass Transfer, 50, 5249-5259.

doi:10.1016/j.ijheatmasstransfer.2007.06.021

Guo, Z-Y., Li, Z-X., 2003, "Size effect on microscale single-phase flow and heat transfer," Int. J. Heat Mass Transfer, 46, 149-159.
doi:10.1016/S0017-9310(02)00209-0

Harms, T.M., Kazmierczak, M., Gerner, F.M., 1999, "Developing Convective Heat Transfer in Deep Rectangular Microchannels," Int. J. of Heat and Fluid Flow, 20, 149-157.

doi:10.1016/S0142-727X(98)10055-3

Kandlikar, S.G., Grande, W.J., 2003, "Evolution of microchannel flow passages-thermohydraulic performance and fabrication technology," Heat Transfer Eng., 24, 3 - 17. doi:10.1080/01457630304040

Kays, W.M., Crawford, M.E., Weigand, B., 2005, Convection Heat and Mass Transfer, 4th ed., McGraw-Hill, Inc, New York, USA.

Korichi, A., Oufer, L., 2005, "Numerical heat transfer in rectangular channel with mounted obstacles on upper and lower walls," Int. J. Thermal Science, 44, 644-655. doi:10.1016/j.ijthermalsci.2004.12.003

Lee, P-S., Garimella, S.V., Liu, D., 2004, "Investigation of heat transfer in rectangular microchannels," Int. J. Heat Mass Transfer, 48, 16881704. doi:10.1016/j.ijheatmasstransfer.2004.11.019

Lee, P-S., Teo, C-J., 2008, "Heat transfer enhancement in microchannels incorporating slanted grooves," Proceedings of the Micro/Nanoscale Heat Transfer International Conference, ASME, 819823.

Lelea, D., Nisho, S., Takano, K., 2004, "The experimental research on microtube heat transfer and fluid flow of distilled water," Int. J. Heat Mass Transfer, 47, 2817-2830.

doi:10.1016/j.ijheatmasstransfer.2003.11.034

Liu, J-T., Peng, X-F., Yan, W-M., 2007, "Numerical study of fluid flow and heat transfer in microchannel cooling passages," Int. J. Heat Mass Transfer, 50, 1885-1864. doi:10.1016/i.ijheatmasstransfer.2006.10.004

Morini, G.L., 2004, "Single-phase convective heat transfer in microchannels: a review of experimental results," Int. J. Thermal Science, 43, 631-651. doi:10.1016/j.ijthermalsci.2004.01.003

Owhaib, W., Palm, B., 2004, "Experimental investigation of single phase convective heat transfer in circular microchannels," Exp. Thermal Fluid Science, 28, 105-110. doi:10.1016/S0894-1777(03)00028-1

Özisik, M.N., 1993, Heat Conduction, 2nd ed., John Wiley and Sons, Inc, New York, USA.

Quadir, G.A., Mydin, A., Seetharamu, K.N., 2001, "Analysis of microchannel heat exchangers using FEM," Int. J. Numerical Methods for Heat and Fluid Flow, 11, 59-75. doi:10.1108/09615530110364097

Shevade, S.S., Rahman, M.M., 2007, "Heat transfer in rectangular microchannels during volumetric heating of the substrate," Int. Com. Heat Mass Transfer, 34, 661-672.

doi:10.1016/j.icheatmasstransfer.2007.02.009

Wang, Y., Ding, G-F., 2008, "Experimental investigation of heat transfer performance for a novel microchannel heat sink," J. Micromechanics and Microengineering, 18, 035021-1-035021-8. doi:10.1088/0960-1317/18/3/035021

Xua, J., Song, Y., Zhang, W., Zhang, H., Gan, Y., 2008, "Numerical simulations of interrupted and conventional microchannel heat sinks," Int. J. Heat Mass Transfer, 51, 5906-5917. doi:10.1016/j.ijheatmasstransfer.2008.05.003 